J. Med. Primatol. 18:397-403 (1989)

\title{
Congenital Limb Malformations in the Free- Ranging Macaques of Kowloon
}

\author{
Frances D. Burton, Leslie Kin Wai Chan \\ Department of Anthropology, University of Toronto, West Hill, Ontario, Canada
}

This paper describes the instances of gross hand and limb malformations in the free-ranging macaques in the forested region of the Kowloon peninsula of Hong Kong. The incidence in this location is compared to that of other macaque groups, most notably the Japanese and rhesus macaques in freeranging and captive conditions. Etiology is linked to what is known about suspected local teratogenic agents, particularly in pesticides and fuel emissions.

Key words: Macaques. Limb. Hand. Foot. Congenital malformation. Macaca Kowloon

\section{INTRODUCTION}

Congenital malformations of the hands, feet, and limbs in macaques are well known [18]. Reports have come from captive populations on rhesus [15-17], and several of the Japanese monkey centers have noted similar anomalous conditions in the hands and feet of Macaca fuscata [10,27]. A variety of explanations for the etiology of limb malformations are in the literature. The Japanese scientists have suggested diet, genetics, and even viruses as responsible for these manifestations $[11,27]$. Since the $1970 \mathrm{~s}$ a growing body of data has recognized the effect of chemical agents which affect the organism in varying degrees during specific susceptible periods of organogenesis $[9,14,25,26]$. We report here on a variety of limb malformations manifest in the free-ranging macaque monkeys of Kowloon (Hong Kong) and suggest possible contributing factors to this condition.

Accepted for publication January 30, 1989.

(C) 1989 Alan R. Liss, Inc. 


\section{MATERIALS AND METHODS}

The habitat of the monkeys in Kowloon is the parklands around the reservoirs which are bounded by major thorough-fares. The area encompasses the five reservoirs in the water system, and comprises over $700 \mathrm{~h}$, under the jurisdiction of the Ministry of Fisheries and Agriculture. This has meant the extension of protection to wildlife within the parklands [1].

There are over 200 monkeys in the study area. They are hybrids of several kinds of macaques indigenous to and released in this geographical zone [21]. The dominant morphotype is Macaca mulatta, which appear to be indigenous [1]. Macaca fascicularis is known to have been released in the 1960 s, and there are still two old females who are probably surviving original animals. In addition, Macaca thibetana and M. fuscata were released in this time period, as was $M$. nemestrina, according to official records. Hence the current population is a mixed one, and it is difficult to ascertain the parentage on observed morphology. These animals free-range within the park system and forage from the 2,536 species of diversified flora [4]. Although they do not receive commercial food from the Ministry, they do receive donations of fruits, vegetables, and sweetmeats from people who use the parks as recreational area. The monkeys are also geophagic. Water is available from natural sources.

While the original observation of malformation in 1984 was serendipitous, the study of limb malformations has become part of the ongoing research on the behaviour and ecology of this population. Observations derive from 1,800 contact hours in three field seasons: 1984, 1986, and 1988. Observations of the anomalies have been based on visual inspection. The malformations observed are documented on videotape and still photographs.

\section{RESULTS}

Seven of the 200 monkeys showed clear, readily identifiable congenital anomalies. As the descriptive terms used for these have often been confused, we follow Homma's classification [10]. These anomalies included ectrodactyly (cleft hand/foot), syndactyly (webbing of skin alone or bone and nails between digits), and hemimelia/phocomelia (half-limb, or "seal flipper") (Table I).

In addition there were between 15-20 possible cases of either campto- or clinodactyly, that is, digits whose phalanges are displaced off the central axis. Since this form of malformation resembles a break due to ontogenetic 
TABLE I. Classification and incidence of limb malformations in the hybrid macaques of Kowloon

\begin{tabular}{lccl}
\hline & Incidence & No. monkeys ${ }^{1}$ & \multicolumn{1}{c}{$\begin{array}{c}\text { Part } \\
\text { limb/hand/foot }\end{array}$} \\
\hline Ectrodactyly & 12 & 3 & Hands and feet \\
Phocomelia & 1 & 1 & Right limb \\
Hemimelia & 2 & 2 & Right limb \\
Syndactyly & 1 & 1 & Left hand \\
\hline
\end{tabular}

${ }^{1}$ The species' identity are not provided as species attribution is not possible since these animals are hybrids of several macaque species over at least 20 years. The figures above represent observations on the whole population.

trauma, we have not itemized them without radiographic confirmation. Just as observational discrimination between malformation and injury is difficult, the converse is equally true: other researchers may have identified as effects of aggression what are actually malformations [e.g., 13]. The inclusion of these cases of phalangeal displacement brings the percent anomalies in the monkeys of Kowloon from $3.5 \%$ to within $11-14 \%$ of the population. Longterm monitoring of the population is being conducted to assess the validity and implications of these frequency estimates, and the behavioural and ecological impacts of congenital limb formation on the Kowloon macaque population.

\section{DISCUSSION}

Most reports do not distinguish between etiology and morphology; hence, each labelled anomaly has been equated to an independent genetic syndrome $[23,24]$. This has complicated the proper estimate of frequency of deformity. There are, however, really two classes of anomaly that can be differentiated on the basis of visual inspection: malformations caused by webbing, and those caused by absence of formation of part of the digit or limb [27].

The frequencies of limb malformation vary widely between captive and free-ranging (although provisioned) macaque populations. The figures for $M$. fuscata fluctuate considerably, depending on which local group is being investigated, and over which historical time period.

Summary of the incidence of limb malformations in 37 troops of Macaca fuscata in Japan [28] showed that 5 troops had over 10\%, 7 troops between $5-10 \%$, and 25 troops no anomalies. In two groups of Macaca fuscata on 
Awajishima Island, there were $14 \%$ and $23 \%$ limb malformations [10]. The Gagyusan troop, for example, prior to 1970 , fluctuated from a low of $13.8 \%$ anomalous births to a high of $40 \%$, whereas the Takasakiyama troops had a prevalence of anomalies of only $1 \%$ in the early 1960s [16]. The frequency of anomalies seen in the monkeys of Kowloon falls within the range of these groups of Japanese macaques.

In Macaca mulatta of Cayo Santiago, a small island off the coast of Puerto Rico, on the other hand, where the provisioned animals are insulated from urban contact, the incidence of malformation is notably different. Over the period 1976 to 1982,963 births were recorded [19]. There were no limb malformations noticed in this large sample, although there were two congenital abnormalities: anencephaly and congenital blindness. An earlier report [15] on free-ranging rhesus monkeys located on Cayo Santiago and $\mathrm{La}$ Paraguera, Puerto Rico, described major teratisms in three infants, including webbed digits and a deformed right hand, plus minor defects (partial webbing of the digits) in several others among 495 births occurring from 1956 to 1963.

The California Primate Research Center [9] reported only one case of hand malformation for 1,698 necropsies. Two cases of split hand were reported, however, for captive rhesus, at the Primate Research Center of the University of Washington in 1971 [16], although no population frequency has been provided. One instance of a foot malformation was found in Macaca fascicularis amongst 24 malformed individuals out of 1,367 births in captive cercopithecids [12].

Longitudinal study of the Barbary macaque, Macaca sylvanus in a freeranging, semiprovisioned population has shown no limb anomalies [2,3]. If malformations of the limbs occurred in Gibraltar between 1970 and 1980, these will have been accompanied by sufficiently severe developmental disruption to terminate the fetus, as no surviving individual manifested recognizable anomalies.

A review of 1,367 births of Old World monkeys in a laboratory setting revealed that inbreeding, where genealogies were known, ". . . did not contribute substantially to the occurrence of malformations" [12:630].

It is also unlikely that hybridization is a contributing factor to limb malformations in the Kowloon macaques since limb malformations are common in macaques of pure parentage such as $M$. fuscata of Japan and macaques in breeding colonies.

The fact that current incidence is significantly higher in $M$. fuscata may relate to the environment in which these animals live. 
Provisioning was originally considered to be the factor responsible [11]. It is unlikely that provisioning is a universal factor [17], since Macaca mulatta on Cayo Santiago and the primate research centers as well as Macaca sylvanus in Gibraltar are to varying degrees provisioned. There are two kinds of provisioning, however: the distribution of commercial diet (Cayo Santiago; the Primate Centers) provides the monkeys with measured nutrients. Monkeys receiving such provender do not depend on foraging.

The other kind of provisioning is sporadic. It may be comprised of fruits and vegetables and/or sweets (candies, sweetmeats) distributed as dietary supplements, or more frequently given as donations by visitors or even researchers (Gibraltar, Kowloon, some Research Centers). The animals in these circumstances, however, must forage for the bulk of their dietary intake.

The epidemiology of malformations in Macaca suggests a variety of environmental agents that may act as contributing factors in limb malformation. There are a great variety of possible teratogens known to induce malformations $[20,25,26]$. Amongst these, lead and pesticides are the most widespread. The Kowloon macaques are exposed to lead emissions from the heavy traffic along a major part of their range. These emissions become available for ingestion directly through inspiration, or indirectly as particles on leaves and drawn up into plant tissues as well as in soil, or in standing water [5]. Residual material from spray on vegetables and fruits are available to the monkeys through food donations, as well as forage. Pesticides are utilized in Kowloon and include petroleum products dicharged along water courses to inhibit mosquito larvae. Since the mid-1960s, residues of pesticides have been found in soil and water as well as in both vertebrates and invertebrates [6] and these include organisms that are prey for these monkeys. Like macaques in other parts of the world [7,22], the monkeys of Kowloon are geophagic. In particular, the red soil consumed by the monkeys may provide them with mineral substances $[8,9]$ but exposes them to additional chemical residues.

\section{ACKNOWLEDGMENTS}

We wish to thank Mr. S. P. Lau, Conservator of Forests, Kowloon, for making the research possible; the Officers of the Ministry of Fisheries and Agriculture and Tony Hanley for assistance. The Center Field Research and the University of Toronto, through its Humanities and Social Sciences Research Grants (University of Toronto), provided funding. In addition, The 
OGS program of the Government of Ontario supported, in part, L.K.W. Chan.

\section{REFERENCES}

1. Burton FD, Chan LKW: Notes on the care of long-tail macaque (Macaca fascicularis) infants by stump-tail macaques. (Macaca thibetana) Can J Zool 65(3):752-755, 1987.

2. Burton FD, Sawchuk LA: Demography of Macaca sylvanus of Gibraltar. Primates 15 : 271-278, 1974.

3. Burton FD, Sawchuk LA: The genetic implications of effective population size for the barbary macaque in Gibraltar. In Fa JE (ed): "The Barbary Macaque: A Case Study in Conservation." New York: Plenum Press, 1984, 307-318.

4. "Checklist of Hong Kong Plants."' Urban Council and Urban Services Department, Hong Kong: Government of Hong Kong, 1967.

5. Department of Health and Social Security: "Lead and Health." London: Her Majesty's Stationery Office, 1980.

6. Edwards CA: "Persistent Pesticides in the Environment," 2nd edition. Cleveland: CRC Press, 1973.

7. Eudey AE: Earth-eating by macaques in Western Thailand: A preliminary analysis. In Chivers DJ, Herbert J (eds): “'Recent Advances in Primatology. 1." New York: Academic Press, 1978, 351-353.

8. Ganzhorn JR: Soil consumption of two groups of semi-free-ranging Lemurs (Lemur catta and Lemur fulvus). Ethology 74:146-154, 1987.

9. Hendrickx AG, Prahalada S: Teratology and embryogenesis. In Dukelow WR, Erwin J (eds): "Comparative Primate Biology, Volume 3: Reproduction and Development." New York: Alan R. Liss, Inc., 1986, 333-362.

10. Homma T: Sequential pattern of limb anomalies in Japanese monkeys on Awajishima Island. Primates 21(1):20-30, 1980.

11. Iwamoto M: Morphological observations on the congenital malformation of limbs in the Japanese monkey. Primates 8:247-279, 1967.

12. Jerome CP: Congenital malformations and twinning in a breeding colony of old world monkeys. Lab Anim Sci 37:624-630, 1987.

13. Kano T: Observations of physical abnormalities among the wild Bonobos (Pan paniscus) of Wamba, Zaire. Am J Phys Anthropol 63:1-11, 1984.

14. Kochhar DM: Abnormal organogenesis in the limbs. In Wilson JG, Fraser FC (eds): "Handbook of Teratology," vol. 2. New York: Plenum Press, 1977, 453-459.

15. Koford CB, Farber PA, Windle WF: Twins and teratisms in rhesus monkeys. Folia Primatol 4:221-226, 1966.

16. Newell Morris L, Kerr B: Split hand and foot anomaly in Macaca mulatta: A report of two cases. Am J Anat 130:481-494, 1971.

17. Newell Morris L: Spontaneous congenital limb malformations in nonprimates: A review of the literature. Teratology 4:335-342, 1971.

18. Pearson K: On the existence of the digital deformity-so-called "lobster claw" in the apes. Ann Eugenics 4:339-340, 1931.

19. Rawlins RG, Kessler M: Congenital and hereditary anomalies in the rhesus monkeys (Macaca mulatta) of Cayo Santiago. Teratology 28:169-174, 1983. 
20. Shepard TH: "Catalog of Teratogenic Agents," 5th Ed. Maryland: The Johns Hopkins University Press, 1986.

21. Southwick C, Southwick K: Polyspecific groups of macaques on the Kowloon Peninsula, New Territories, Hong Kong. Am J Primatol 5:17-24.

22. Sultana CJ, Marriott BM: Geophagia and related behavior of rhesus monkeys (Macaca mulatta) on Cayo Santiago Island, Puerto Rico. Int J Primatol 3:338, 1982.

23. Temtamy SA, McKusick VA: "The Genetics of Hand Malformations." New York: Alan R. Liss, Inc., 1978.

24. Temtamy SA: The genetics of hand malformations: Updated. Cong Anom 25:73-92, 1985.

25. Wilson JG: "Environment and Birth Defects." New York: Academic Press, 1973.

26. Wilson JG: Environmental chemicals. In Wilson JG, Fraser FC (eds): "Handbook of Teratology," Vol. 1. New York: Plenum Press, 1977, 357-385.

27. Yoshihiro S: Congenital limb malformations of the japanese monkey. Teratology 22(1):26A, 1980.

28. Yoshihiro S, Goto S, Minezawa M, Muramatasu M, Saito Y, Sugita H, Nigi H: Frequency of occurrence, morphology, and causes of congenital malformation of limbs in the japanese monkey. Ecotoxicol Environ Safety 3:458-470, 1979.

Frances D. Burton, Ph.D., Dept. of Anthropology/University of Toronto, West Hill, Ontario, M1C 1A4 Canada 